\title{
PHYLOGENETIC IMPLICATIONS OF CHLOROPLAST DNA RESTRICTION SITE VARIATION IN THE MUTISIEAE (ASTERACEAE) ${ }^{1}$
}

\author{
Robert K. JANSEN ${ }^{2}$ AND JefFrey D. PALMER ${ }^{3}$ \\ ${ }^{2}$ Department of Ecology and Evolutionary Biology, The University of Connecticut, Box U-42, \\ Storrs, Connecticut 06268; and ${ }^{3}$ Department of Biology, University of Michigan, \\ Ann Arbor, Michigan 48109
}

\section{A B S T R A C T}

Phylogenetic relationships among 13 species in the tribe Mutisieae and a single species from each of three other tribes in the Asteraceae were assessed by chloroplast DNA restriction site mapping. Initially, 211 restriction site mutations were detected among 16 species using 10 restriction enzymes. Examination of 12 of these species using nine more enzymes revealed 179 additional restriction site mutations. Phylogenetic analyses of restriction site mutations were performed using both Dollo and Wagner parsimony, and the resulting monophyletic groups were statistically tested by the bootstrap method. The phylogenetic trees confirm an ancient evolutionary split in the Asteraceae that was previously suggested by the distribution of a chloroplast DNA inversion. The subtribe Barnadesiinae of the tribe Mutisieae is shown to be the ancestral group within the Asteraceae. The molecular phylogenies also confirm the paraphyly of the Mutisieae and provide statistical support for the monophyly of three of its four currently recognized subtribes (Barnadesiinae, Mutisiinae, and Nassauviinae). The fourth subtribe, Gochnatiinae, is shown to be paraphyletic. Within the subtribes, several closely related generic pairs are identified. Chloroplast DNA sequence divergence among genera of the Asteraceae ranges between 0.7 and $5.4 \%$, which is relatively low in comparison to other angiosperm groups. This suggests that the Asteraceae is either a relatively young family or that its chloroplast DNA has evolved at a slower rate than in other families.

THE ASTERACEAE is one of the largest and most successful flowering plant families, consisting of approximately 1,100 genera and 20,000 species (Cronquist, 1981). Several specialized morphological features (capitulum, highly reduced and moditied flowers, inferior ovary, ovule basal and erect, connate anthers, etc.) strongly support the naturalness of the family. Recent angiosperm classification systems (Thorne, 1976; Dahlgren, 1980; Takhtajan, 1980; Cronquist, 1981) emphasize the phylogenetic isolation of the family by placing it in a monotypic order at the most advanced

\footnotetext{
${ }^{1}$ Received for publication 27 August 1987; revision accepted 5 January 1988.

We thank the following individuals for providing seeds or live plant material: James M. Affolter, Donald G. Huttleston, Charles Jeffrey, David J. Keil, Guy L. Nesom, H. James Price, Roger W. Sanders. We also thank H. Tucker for technical assistance, $K$. Holsinger and S. Pacala for assistance with the phylogenetic analyses, $K$. Bremer for providing an unpublished cladistic analysis of the Asteraceae, $\mathbf{K}$. Holsinger for critically reading the manuscript, and M. Hommel and the Matthaei Botanical Garden for expert care and growth of plants. This study was supported by a grant from the National Science Foundation (BSR8415934).
}

position in the class Dicotyledonae. In addition to its large size, the Asteraceae has a cosmopolitan distribution and is highly diversified in its habitat preferences and life forms. Furthermore, although there is some controversy concerning the age of the family (Turner, 1977; Boulter et al., 1978), fossil evidence (Cronquist, 1977; Muller, 1981) and biogeographical considerations (Raven and Axelrod, 1974) suggest that the Asteraceae originated in the middle to upper Oligocene (30 million years ago) and subsequently underwent rapid and extensive morphological, chemical, and biological diversification. This explosive radiation has posed special problems for elucidating phylogenetic relationships at higher taxonomic levels.

During the past 30 years, six markedly different schemes of phylogenetic relationships among the subfamilies and tribes of Asteraceae have been proposed (Cronquist, 1955, 1977; Carlquist, 1976; Wagenitz, 1976; Jeffrey, 1978; Thorne, 1983; Bremer, 1987). Although there is general agreement that two distinct subfamilies (Asteroideae and Cichorioideae) should be recognized, there is no consensus concerning 
TABLE 1. Sources of chloroplast DNA from species of Asteraceae and outgroup families

\begin{tabular}{|c|c|c|c|}
\hline Species & Source $^{\mathrm{a}}$ & Voucher information ${ }^{b}$ & Geographic origin \\
\hline \multicolumn{4}{|l|}{ Asteraceae } \\
\hline \multicolumn{4}{|l|}{ Mutisieae } \\
\hline \multicolumn{4}{|l|}{ Barnadesiinae } \\
\hline 1. Barnadesia caryophylla & MBG & J907(MICH) & Peru \\
\hline 2. Chuquiragua oppositifolia & UC & $83-303$ & Chile \\
\hline 3. Dasyphyllum diacanthoides & $\mathrm{UC}$ & $62-28851$ & unknown \\
\hline \multicolumn{4}{|l|}{ Gochnatiinae } \\
\hline 4. Ainsliaea dissecta & KEW & $110-80-00757$ & Japan \\
\hline 5. Gochnatia paucifolia & FTG & $64-276$ & Peru \\
\hline 6. Stifftia chrysantha & KEW & $386-39-38601$ & Brazil \\
\hline 7. Onoseris hyssopifolia & $\mathrm{LG}$ & J921(MICH) & Ecuador \\
\hline \multicolumn{4}{|l|}{ Mutisiinae } \\
\hline 8. Gerbera jamesonii & $\mathrm{MBG}$ & J915(MICH) & South Africa \\
\hline 9. Leibnitzia seemannii & Nesom & N5084(TEX) & Mexico \\
\hline 10. Mutisia acuminata & $\mathrm{UC}$ & $64-1510$ & Chile \\
\hline \multicolumn{4}{|l|}{ Nassauviinae } \\
\hline 11. Acourtia microcephala & Keil & $\mathrm{K} 18945(\mathrm{OBI})$ & California \\
\hline 12. Perezia multiflora & KEW & $280-64-28004$ & Brazil \\
\hline 13. Trixis californicum & Keil & $\mathrm{K} 18528(\mathrm{OBI})$ & California \\
\hline \multicolumn{4}{|l|}{ Cichorieae } \\
\hline 14. Lactuca sativa & GS & none & unknown \\
\hline \multicolumn{4}{|l|}{ Heliantheae } \\
\hline 15. Helianthus annuus & Price & PHa89(TAES) & unknown \\
\hline \multicolumn{4}{|l|}{ Cardueae } \\
\hline 16. Carthamnus tinctorius & USDA & PI198990 & Israel \\
\hline \multicolumn{4}{|l|}{ Dipsacaceae } \\
\hline 17. Cephalaria leucantha & MBG & J930(MICH) & Spain \\
\hline 18. Dipsacus sativus & MBG & J931(MICH) & Asia \\
\hline \multicolumn{4}{|l|}{ Rubiaceae } \\
\hline 19. Pentas lanceolata & MBG & J914(MICH) & Africa \\
\hline 20. Psychotria bacteriophila & MBG & 66517 & Comoros Island \\
\hline
\end{tabular}

${ }^{a}$ FTG = Fairchild Tropical Garden, GS = Grocery Store, Keil = Dr. David J. Keil, KEW = Kew Botanical Garden, LG $=$ Longwood Garden, MBG = Matthaei Botanical Garden, Nesom = Dr. Guy L. Nesom, Price = Dr. H. James Price, UC = University of California Botanical Garden, USDA = United States Department of Agriculture.

${ }^{b}$ Numbers preceded by a letter indicate collector $(\mathrm{J}=$ Jansen, $\mathrm{K}=\mathrm{Keil}, \mathbf{P}=$ Price $)$ and collection number. All other numbers are accession numbers for live plants at botanical gardens. Standard herbarium acronyms (Stafleu, 1981) that follow collection numbers indicate the location of voucher specimens.

the circumscription of the subfamilies, the number of monophyletic tribes, and the relationships among the 12 to 17 recognized tribes. These previous intrafamilial classifications relied on more traditional data, including characters derived from anatomical, chromosomal, embryological, morphological, palynological, phytochemical, and ultrastructural studies. Furthermore, only the most recent reassessment of relationships (Bremer, 1987) has applied explicit cladistic methodology in developing hypotheses of evolutionary relationships.

We are performing cladistic analyses of chloroplast DNA (cpDNA) mutations in order to clarify phylogenetic relationships among the subfamilies and tribes of the Asteraceae. The conservative organization and evolution of cpDNA among angiosperms (Palmer, 1985a, b) makes this molecule well suited for com- parative systematic investigations. Previous studies have clearly demonstrated the potential of cpDNA for resolving evolutionary relationships among species in such genera as Brassica (Palmer et al., 1983a), Clarkia (Sytsma and Gottlieb, 1986a, b), Cucumis (Perl-Treves and Galun, 1985), Linum (Coates and Cullis, 1987), Lycopersicon (Palmer and Zamir, 1982), Lisianthius (Sytsma and Schaal, 1985), Nicotiana (Kung, Zhu, and Chen, 1982; Salts et al., 1984), Pisum (Palmer, Jorgensen, and Thompson, 1985), Solanum (Hosaka et al., 1984; Hosaka, 1986), and Triticum (Bowman, Bonnard, and Dyer, 1983; Tsunewaki and Ogihara, 1983). Our studies are the first to use cpDNA to assess phylogenetic relationships at higher taxonomic levels.

Our previous studies (Jansen and Palmer, $1987 \mathrm{a}, \mathrm{b})$ revealed that there are two chloroplast genome arrangements in the Asteraceae. 
Chloroplast DNAs from species in the subtribe Barnadesiinae (Mutisieae) are colinear with cpDNAs of almost all land plants, including 10 families putatively related to the Asteraceae. All other Asteraceae, including 57 genera from all currently recognized tribes (sensu Jeffrey, 1978), share a derived 22 kilobase (kb) inversion. Two alternative explanations were proposed for the phylogenetic distribution of the inversion. The most parsimonious interpretation is that the Barnadesiinae primitively lacks the inversion and that this derived mutation groups all other Asteraceae together. This single character would then position the Barnadesiinae at an ancestral position in the family and indicate that the tribe Mutisieae is paraphyletic. Alternatively, the inversion could have occurred in the common ancestor of the Asteraceae and subsequently been reversed in the Barnadesiinae.

In this paper, we perform rigorous cladistic analyses of a large number of restriction site mutations to decide between these alternative phylogenetic explanations for the distribution of the $22 \mathrm{~kb}$ cpDNA inversion. Our results also provide insights into evolutionary relationships within the Mutisieae, overall cpDNA sequence divergence in the Asteraceae, and the limitations of Wagner and Dollo parsimony in analyzing restriction site data at higher taxonomic levels.

MATERIALS AND METHODS-The sources of plant material for the 16 species of Asteraceae and four outgroup species included in this study are given in Table 1. Chloroplast DNAs were isolated by the sucrose gradient technique (Palmer, 1986a). Where tissue amounts were limited, total DNA was isolated using the procedure of Saghai-Maroof et al. (1984) and further purified in $\mathrm{CsCl} /$ ethidium bromide gradients. Restriction endonuclease digestions, agarose gel electrophoresis, bidirectional transfer of DNA fragments from agarose gels to Zetabind (AMF CUNO) nylon filters, labelling of recombinant plasmids by nick-translation, filter hybridizations, and autoradiography were performed as described in Palmer (1986a) and Jansen and Palmer (1987a). A total of 22 cloned restriction fragments of lettuce cpDNA (Fig. 1 ; Jansen and Palmer, 1987a) were used in filter hybridization experiments to map sites in cpDNAs of the 20 examined species. Restriction sites for 10 enzymes were mapped for DNAs of all 20 species and nine additional enzymes were mapped for 13 of these species. The mapping strategy for species of Asteraceae was simplified by constructing complete restriction maps of lettuce cpDNA using the

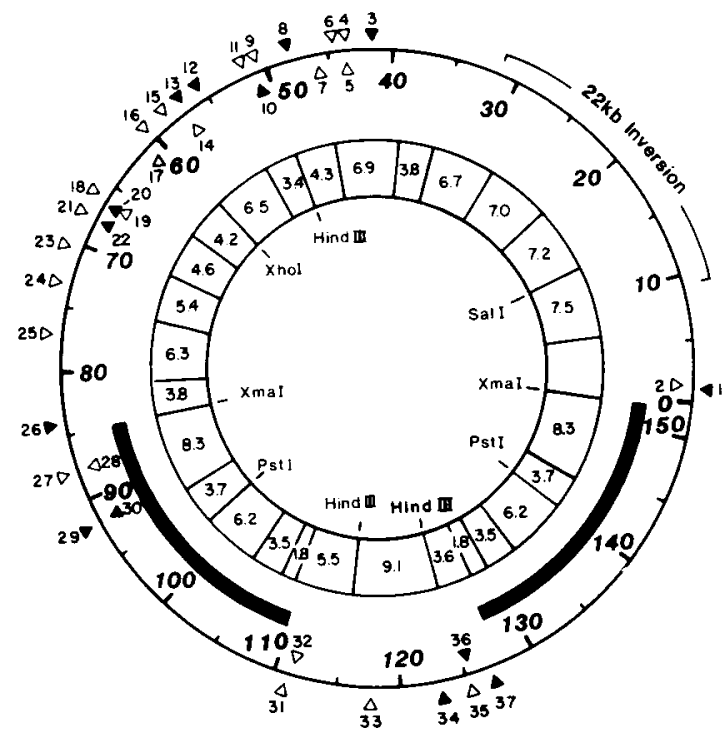

Fig. 1. Restriction site map of lettuce cpDNA showing the location of the 22 cloned restriction fragments used as hybridization probes. All restriction sites are for SacI except where indicated. The two, heavy black lines indicate the extent of the inverted repeat. Fragment sizes and scale are given in kilobases $(\mathrm{kb})$. The location of the 37 length mutations (Table 1) is indicated by open triangles (deletions) and closed triangles (insertions).

overlap hybridization procedure (Palmer, 1986a; Jansen and Palmer, 1987a). Chloroplast DNAs from all species including lettuce were run on one gel, transferred to a nylon filter, and hybridized to the 22 cloned restriction fragments (Fig. 1) of lettuce cpDNA. Restriction site mutations in cpDNÂs of all species were then scored relative to mapped restriction sites of lettuce. Restriction sites in the region of the $22 \mathrm{~kb}$ cpDNA inversion were not used in phylogenetic analyses because of the uncertainty of aligning rearranged sites.

The restriction site data were analyzed on a NCR microcomputer using two different parsimony methods. Wagner parsimony was performed using PAUP (Phylogenetic Analysis Using Parsimony, version 2.4.2, developed by D. Swofford). The most parsimonious tree was obtained by implementing the branch-andbound option (Hendy and Penny, 1982), which performs an exhaustive evaluation of tree topologies to find the shortest tree. Dollo parsimony, which prohibits parallel site gains but allows parallel site losses, was also used. DeBry and Slade (1985) argue that Dollo parsimony is a more consistent and efficient estimator of phylogenetic relationships for restriction site data. Their arguments are based on the fact that parallel site losses are much more probable 
TABLE 2. Chloroplast DNA restriction-fragment length variation in the Mutisieae. ${ }^{\text {a }}$ Length mutations in the $22 \mathrm{~kb}$ inversion region are not given

\begin{tabular}{|c|c|c|c|c|c|c|c|}
\hline Region ${ }^{\mathrm{b}}$ & Variation ${ }^{\mathrm{C}}$ & Size (bp) & Species" & Region $^{b}$ & Variation $^{c}$ & Size (bp) & Species \\
\hline 1. $0.9-1.3$ & insertion & 150 & 4 & 20. $66.0-66.9$ & insertion & 200 & 4 \\
\hline 2. $0.9-1.3$ & deletion & 100 & 13 & 21. $66.5-67.1$ & deletion & 150 & 7 \\
\hline 3. $41.5-42.2$ & insertion & 100 & 11 & 22. $66.5-67.3$ & insertion & 100 & 6 \\
\hline 4. $43.6-44.6$ & deletion & 100 & 2 & 23. $70.5-71.4$ & deletion & 200 & 8,9 \\
\hline 5. $43.6-44.9$ & deletion & 200 & 12 & 24. $73.4-73.9$ & deletion & 100 & 4 \\
\hline 6. $44.4-44.7$ & deletion & 250 & 7 & 25. $77.5-77.6$ & deletion & 200 & 14 \\
\hline 7. $45.9-46.0$ & deletion & 100 & 1 & 26. $84.0-84.4$ & insertion & 100 & 4 \\
\hline 8. $48.1-48.7$ & insertion & 100 & 6 & 27. $87.6-89.0$ & deletion & 300 & 10 \\
\hline 9. $49.5-50.8$ & deletion & 200 & 12 & 28. $87.6-89.0$ & deletion & 400 & 2 \\
\hline 10. $50.8-51.2$ & insertion & 100 & 6 & 29. $91.8-92.5$ & insertion & 100 & 11 \\
\hline 11. $50.8-51.4$ & deletion & 500 & $1-3$ & 30. 91.7-92.7 & insertion & 100 & 1 \\
\hline 12. $55.2-55.6$ & insertion & 100 & 11 & 31. $110.6-111.1$ & deletion & 200 & 10 \\
\hline 13. $57.0-57.6$ & insertion & 100 & 1 & 32. $111.1-111.9$ & deletion & 300 & 12 \\
\hline 14. $57.0-57.6$ & deletion & 100 & 7 & 33. $117.4-118.9$ & deletion & 150 & 4 \\
\hline 15. $58.4-59.0$ & deletion & 100 & 5,9 & 34. 123.1-124.4 & insertion & 200 & 6 \\
\hline 16. $60.4-60.6$ & deletion & 200 & 4 & 35. $125.0-126.7$ & deletion & 200 & 8,9 \\
\hline 17. $60.4-61.1$ & deletion & 500 & 12 & 36. $125.3-126.0$ & insertion & 1,200 & 7 \\
\hline 18. $65.8-66.0$ & deletion & 250 & 9 & 37. $126.7-127.1$ & insertion & 100 & 4 \\
\hline 19. $66.0-66.7$ & deletion & 600 & 3 & & & & \\
\hline
\end{tabular}

a Size variation less than 100 bp could not be detected; Lactuca (Cichorieae) was also included.

${ }^{b}$ See Fig. 1 for map coordinates in $\mathrm{kb}$.

c The direction of evolutionary change of size variation was determined by outgroup comparison using the Barnadesiinae as the outgroup. Length mutation 11 cannot be polarized in this manner, but it probably represents a deletion.

d See Table 1.

than parallel site gains. Wagner parsimony gives equal weight to these two types of homoplasious changes. Dollo parsimony was performed using PHYLIP (Phylogeny Inference Package, version 2.7 , developed by J. Felsenstein) and the global option was used to find the shortest tree. The bootstrap method (Felsenstein, 1985) in PHYLIP was used to determine confidence intervals on the phylogenies. One hundred bootstrap replicates were performed and majority-rule consensus trees were constructed using both Wagner and Dollo parsimony.

The direction of evolutionary change of restriction sites was determined by outgroup comparison (Stevens, 1980; Watrous and Wheeler, 1981). There is substantial disagreement concerning the in terfamilial relationships of the Asteraceae (reviewed in Cronquist, 1955, 1977; Carlquist, 1976; Wagenitz, 1976, 1977; Bremer, 1987). The Calyceraceae, Campanulaceae, Dipsacaceae, Lobeliaceae, and Rubiaceae have been proposed most frequently as the closest relatives. Because this problem has not been satisfactorily resolved, we believed it appropriate to use representatives of all of the families. Unfortunately, the Campanulaceae and Lobeliaceae have multiple rearrangements in their chloroplast genomes (Jansen and Palmer, unpublished data), making it difficult to align restriction sites in these families relative to sites in the Asteraceae. The Calyceraceae was not selected because we were unable to obtain material of this small South American family. Thus, we have selected four species from the remaining two families, Dipsacaeae and Rubiaceae. Of these, the Rubiaceae appears the more appropriate outgroup because it has more restriction sites in common with species of Asteraceae.

RESULTS-Restriction fragment length variation-Thirty-seven deletions and insertions ranging in size from 100 to 1,200 basepairs (bp) were detected in cpDNAs in the Asteraceae (Table 2). The majority (28) of these length polymorphisms were between 100 and $200 \mathrm{bp}$. Since most cpDNA length mutations are 1-10 bp in size (reviewed in Palmer, 1985a), and since we could not detect length mutations smaller than $100 \mathrm{bp}$, we have underestimated the actual extent of restriction fragment length variation. The frequency of length mutations within the three major regions of the chloroplast genome (inverted repeat, small and large single copy regions) is approximately the same except for one portion of the large single copy region (LSC) (Fig. 1; Table 2). Only 17 length mutations (numbers 1, 2, 23-37) occur in a 74 $\mathrm{kb}$ portion of the chloroplast genome, whereas 20 length mutations (numbers 3-22) are located in a $30 \mathrm{~kb}$ portion of the LSC region. The concentration of length mutations in this $30 \mathrm{~kb}$ region is not surprising because there is substantial spacer sequence in this portion of the chloroplast genome (Shinozaki et al., 1986; 
Jansen and Palmer, 1987a), which could easily accommodate any disruptive effects of insertions or deletions.

Length mutations were detected in cpDNAs of 14 species of the Asteraceae (Table 2). Ainsliaea (Mutisieae, Gochnatiinae) has accumulated the most length polymorphisms. Only four length mutations of the same size and in the same location are shared by more than one species (Table 2; numbers $11,15,23$, and 35). Although length mutations were not used in any phylogenetic analyses, phylogenies constructed from restriction site mutations (see below) show that species sharing three of the length mutations (Table 2; numbers 11, 15, and 35) are closely related, suggesting that these changes are homologous.

Because of the large number of restriction sites mapped for each species (approximately 600 ), it was possible to map accurately the location of many of the 37 length mutations. In several instances, this information was valuable for deciding whether a restriction site change was due to a base substitution or a deletion/insertion. For example, Gochnatia and Perezia share a site loss for the enzyme BstXI within the $6.9 \mathrm{~kb}$ SacI fragment. Perezia has a 200 bp deletion (Table 2; number 5) that maps within the region where the BstXI site occurs in other species of Asteraceae. Thus, it seems likely that this shared site loss is not due to a homologous base substitution. In instances where such distinctions could be made, taxa which shared restriction site changes due to a length mutation were not included in phylogenetic analyses.

Phylogenetic analysis of restriction site $m u$ tations - The investigation of restriction site variation was performed in two phases. Initially, cpDNAs from 16 species of Asteraceae (13 species from the Mutisieae and one species from each of three other tribes-Cardueae, Cichorieae, and Heliantheae) and four outgroup species in the Dipsacaceae and Rubiaceae were analyzed with 10 enzymes that recognize sixbase pair sites (Table 3 ). Approximately 213 sites were mapped in cpDNAs of each species and a total of 211 site changes were detected in 16 species of the Asteraceae. Only 55 of these mutations were phylogenetically informative, i.e., shared by two or more species. The direction of evolutionary change of the restriction sites was determined by comparison with the four outgroup species in the Dipsacaceae and Rubiaceae. For 51 of the 55 informative sites, the four outgroup species agreed with respect to the direction of change and only four mutations (numbers $1,34,42,43$ ) were vari- able among the outgroups. For mutation number 1 , it was possible to use the Campanulaceae and Lobeliaceae as additional outgroups because this restriction site change occurs in an unrearranged region of the chloroplast genome. All four genera in these families (Campanula, Jasione, Phyteuma, and Lobelia) agreed with respect to the polarity of this mutation. The state occurring in three of the four genera of the Dipsacaceae and Rubiaceae was considered to be ancestral for the remaining three restriction site mutations. Therefore, a single ancestral state was used for all mutations in subsequent phylogenetic analyses. The data were subjected to Wagner and Dollo parsimony using the PAUP and PHYLIP programs, respectively.

The Wagner parsimony analysis resulted in a single most parsimonious tree (Fig. 2) requiring a total of 247 steps. This tree has a consistency index of 0.85 (Kluge and Farris, 1969 ) and $15 \%$ homoplasy. Our calculations of the consistency index and homoplasy include unique mutations (autapomorphies). Homoplasious site changes include 27 parallel losses, two parallel gains, five gains/losses, and two losses/gains. The tree shows an initial dichotomy separating the subtribe Barnadesiinae (Mutisieae) from the rest of the Asteraceae, including the three other subtribes of Mutisieae. This is the same evolutionary split that is defined by a cpDNA inversion (Jansen and Palmer, 1987b). There are a total of six derived site changes, five of which are gains, that group all Asteraceae together relative to the Barnadesiinae. In addition, three of the subtribes of Mutisieae (Barnadesiinae, Mutisiinae, and Nassauviinae) are monophyletic, whereas the Gochnatiinae forms an unresolved trichotomy, suggesting that it is a paraphyletic group. Within the Mutisieae there is also support for a close relationship between the Mutisiinae and Nassauviinae.

The restriction site data were also analyzed using the global swapping option of Dollo parsimony and a single most parsimonious tree was produced (Fig. 3). This tree requires 254 mutations and has a consistency index of 0.83 and $17 \%$ homoplasy. In this case, ail homoplasious site changes are parallel losses or gains/ losses. The Dollo tree (Fig. 3) has the same topology as the Wagner tree (Fig. 2) except that the four genera in the Gochnatiinae are monophyletic.

The initial dichotomy separating the Barnadesiinae from the rest of the Asteraceae does not agree with any previous schemes of phylogenetic relationships in the family, including those proposed by Cronquist $(1955,1977)$, 
TABle 3. Chloroplast DNA restriction site mutations used in phylogenetic analyses of 16 species in the Asteraceae (Table I) using 10 enzymes. Site changes in the $22 \mathrm{~kb}$ inversion region were not used because of the uncertainty in aligning rearranged sites. Only mutations shared by more than one species are listed. Mutations (50) shared by all species of Asteraceae relative to outgroup families and those (156) found in only a single species are not listed. Map coordinates in $\mathrm{kb}$ indicate the location of restriction site mutations (see Fig. 1). Mutations are listed with ancestral fragment(s) first, followed by the derived fragment(s). Ancestral states were determined by outgroup comparison (see Methods). Taxa sharing derived mutations are indicated by the numbers given in Table 1

\begin{tabular}{|c|c|c|c|c|c|c|c|}
\hline Enzyme & Region $^{b}$ & Mutation & Mutated DNAs & Enzyme* & Region $^{b}$ & Mutation & Mutated DNAs \\
\hline 1. $\mathrm{A}$ & 82.3 & $0.9+0.5=1.4$ & 8,9 & 29. E & $90.9^{* *}$ & $1.1=0.7+0.4$ & $4-6$ \\
\hline 2. $\mathrm{A}$ & 91.2 & $6.3=3.5+2.8$ & $1-3$ & 30. $\mathrm{E}$ & $91.0^{* *}$ & $1.1=0.8+0.3$ & $12,14-16$ \\
\hline 3. $\mathrm{A}$ & 110.2 & $9.2=7.2+2.0$ & $2,5-11,13-16$ & 31. E & 115.0 & $22+1.5=24$ & 4,7 \\
\hline 4. $\mathrm{A}$ & 117.4 & $7.2+2.3=10.5$ & $12,13,16$ & 32. $\mathrm{E}$ & 119.2 & $22=17.5+4.2$ & $8-10$ \\
\hline 5. A & 123.8 & $4.0+3.3=7.3$ & 7,9 & 33. $\mathrm{E}$ & 110.6 & $4.0+1.5=5.5$ & $2,7,12,14$ \\
\hline 6. A & 35.2 & $7.8+3.2=11.0$ & $8-13$ & 34. E & 44.9 & $14.5+7.5=22$ & $2,3,16$ \\
\hline 7. $\mathrm{A}$ & $39.6^{*}$ & $6.9=6.1+0.8$ & 8,9 & 35. E & 47.7 & $9.3=6.5+2.8$ & $1-3$ \\
\hline 8. A & 54.0 & $13.0=8.4+4.6$ & $1-3$ & 36. $\mathrm{E}$ & $58.7^{* *}$ & $3.3=2.8+0.5$ & $4-16$ \\
\hline 9. $\mathrm{A}$ & 62.8 & $4.3+0.4=4.7$ & $4-7,14-16$ & 37. $\mathrm{E}$ & 70.0 & $11.7=11.0+0.7$ & 8,9 \\
\hline 10. A & 75.9 & $1.0+0.6=1.6$ & $8,9,12$ & 38. $\mathrm{F}$ & 6.2 & $10.0+5.4=15.4$ & 8,9 \\
\hline 11. A & 80.2 & $0.5+0.3=0.8$ & 12,13 & 39. $\mathrm{F}$ & 28.4 & $6.4=3.4+3.0$ & 8,9 \\
\hline 12. $\mathrm{B}$ & 146.0 & $18=11.5+6.5$ & $1-3$ & 40. $F$ & 40.2 & $8.4=6.9+1.5$ & $4-16$ \\
\hline 13. $\mathrm{B}$ & 126.1 & $6.7+3.5=10.2$ & $8,10,11-14$ & 41. $G$ & 5.8 & $12=7.5+4.5$ & 8,9 \\
\hline 14. $B$ & 2.7 & $9.0=5.6+3.4$ & $1-3$ & 42. $\mathrm{G}$ & 68.7 & $7.2+1.0=8.2$ & $1,8-13$ \\
\hline 15. B & 34.9 & $7.6+2.4=10.0$ & $6,11-14$ & 43. $\mathrm{G}$ & 73.1 & $11.7+3.3=14.0$ & $1,12,16$ \\
\hline 16. $\mathrm{B}$ & 73.6 & $24=16+8$ & $8-13$ & 44. $\mathrm{H}$ & 91.9 & $3.7+1.7=5.4$ & $1-3,5,8-10$ \\
\hline 17. $\mathrm{C}$ & 99.2 & $6.5+2.2=8.7$ & 1,16 & 45. $\mathrm{H}$ & $90.7^{* *}$ & $5.7+0.8=6.5$ & $3,9,15$ \\
\hline 18. C & 124.6 & $14.2=9.0+5.2$ & 1,2 & 46. I & 100.0 & $6.0=4.2+1.8$ & $1-3$ \\
\hline 19. C & 60.3 & $2.9=1.6+1.3$ & $1-3$ & 47. I & $112.2^{*}$ & $6.0=3.4+2.6$ & 8,9 \\
\hline 20. C & 77.1 & $3.6+3.0=6.6$ & 4,5 & 48. I & 2.9 & $8.3=6.7+1.6$ & $1-3$ \\
\hline 21. $\mathrm{C}$ & 80.1 & $12.0+3.0=15.0$ & 1,7 & 49. I & 56.3 & $1.9+0.6=2.5$ & 2,8 \\
\hline 22. $\mathrm{D}$ & 102.3 & $10.0=9.6+0.4$ & $14-15$ & 50. I & 66.0 & $4.9=3.7+1.2$ & $5-16$ \\
\hline 23. $\mathrm{D}$ & 109.5 & $4.0=2.2+1.8$ & $4-13,15,16$ & 51. I & 70.3 & $0.6+0.3=0.9$ & $1-3,8,9$ \\
\hline 24. D & 111.6 & $2.1+0.6=2.7$ & $9,14-16$ & 52. J & 83.6 & $10.0+2.5=12.5$ & 12,14 \\
\hline 25. D & 112.2 & $6.7=6.1+0.6$ & $4-11,13$ & 53. J & 55.6 & $10.6=8.8+1.8$ & 6,9 \\
\hline 26. D & 113.1 & $6.1=5.2+0.9$ & $4-6$ & 54. J & 74.5 & $6.3+5.4=11.7$ & $1,8,9$ \\
\hline 27. $\mathrm{D}$ & 118.1 & $6.1+9.7=15.8$ & 8,9 & 55. J & 80.7 & $6.3+2.5=8.8$ & $1-3,6$ \\
\hline 28. D & 78.1 & $10.4=5.8+4.6$ & $4-16$ & & & & \\
\hline
\end{tabular}

anzyme abbreviations: $\mathrm{A}=\mathrm{AvaI}$; $\mathrm{B}=$ Bam HI; $\mathrm{C}=$ BanI; D $=$ BstXI; $\mathrm{E}=\mathrm{EcoRV} ; \mathrm{F}=\mathrm{HaeII}$; $\mathrm{G}=\mathrm{HindII}$; H $=$ NcoI; I = NsiI; J = SacI.

b Ambiguity concerning region because two* or three** restriction fragments are unordered.

Carlquist (1976), Jeffrey (1978), and Wagenitz (1976). Because our results are so strikingly different from those of previous workers, we analyzed our data in greater detail to determine the robustness of the initial evolutionary split in the Asteraceae. The forced topology option of PAUP showed that it requires 252 steps (five additional mutations) to force a tree topology that agrees with previous workers, i.e., that the subtribes Gochnatiinae, Mutisiinae, and Nassauviinae are more closely related cladistically to the Barnadesiinae than to the other tribes of Asteraceae. Hence, it takes five additional steps to break the initial dichotomy in Fig. 2, 3. We then attempted an exhaustive search to determine the total number of trees between 247 and 252 steps using the branch-and-bound option. Although PAUP has a limit of 100 trees that are saved during any analysis, the number of equally parsimonious trees is displayed on the screen in the interactive mode. At 248, 249, and 250 steps there were 21,129 , and 529 equally parsimonious trees, respectively. There were a minimum of 8071 trees at 251 and 252 steps. Unfortunately, we were unable to determine the exact number of trees of these two lengths because we were not observing the display screen when this $12-18 \mathrm{hr}$ analysis was completed. We can conclude, however, that it is necessary to reject at least 8750 trees before accepting the previously proposed hypotheses of phylogenetic relationships in the Asteraceae.

The bootstrap sampling method (Felsenstein, 1985) was used to place confidence intervals on monophyletic groups. One hundred replicate samples were performed using both Dollo and Wagner parsimony and majorityrule consensus trees were constructed. Both consensus trees had the same topology as the tree generated by global swapping using Dollo parsimony (Fig. 3). The confidence intervals for each monophyletic group using Wagner and Dollo parsimony are given in percentages in Fig. 2, 3, respectively. The most important 

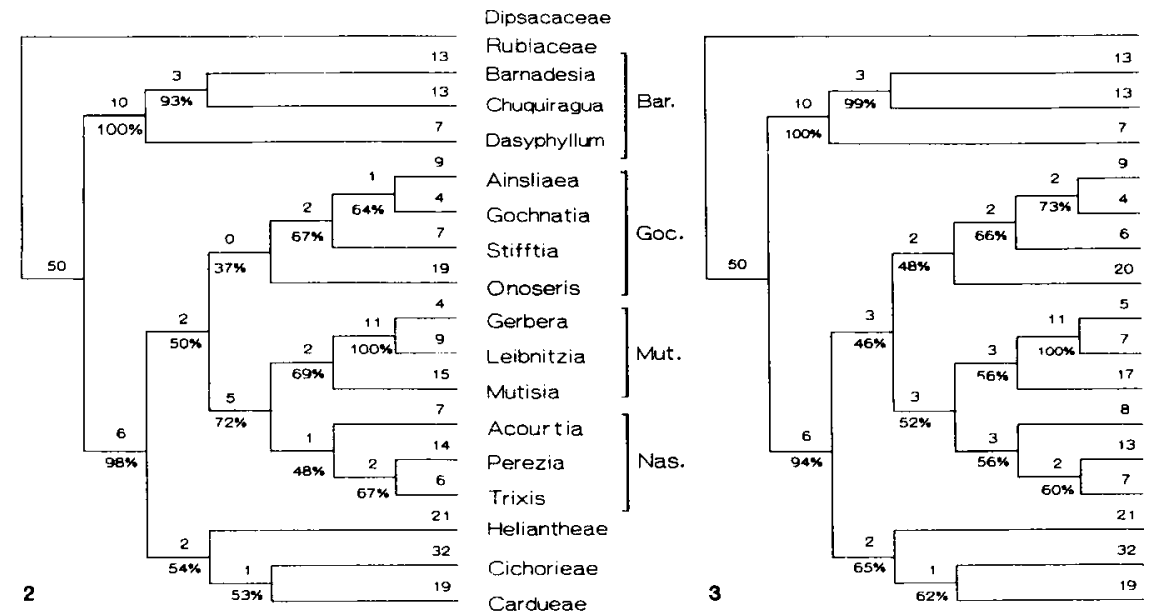

Dipsacaceae

Rubiaceae

Barnadesia

Chuquiragua Bar.

Dasyphyllum

Ainsliaea

Gochnatia Goc.

Stifftia

Onoseris

Gerbera

Leibnitzia

Mutisia

Acourtia

Perezia Nas.

Cardueae

Trixis

Heliantheae

Cichorieae

Cardueae
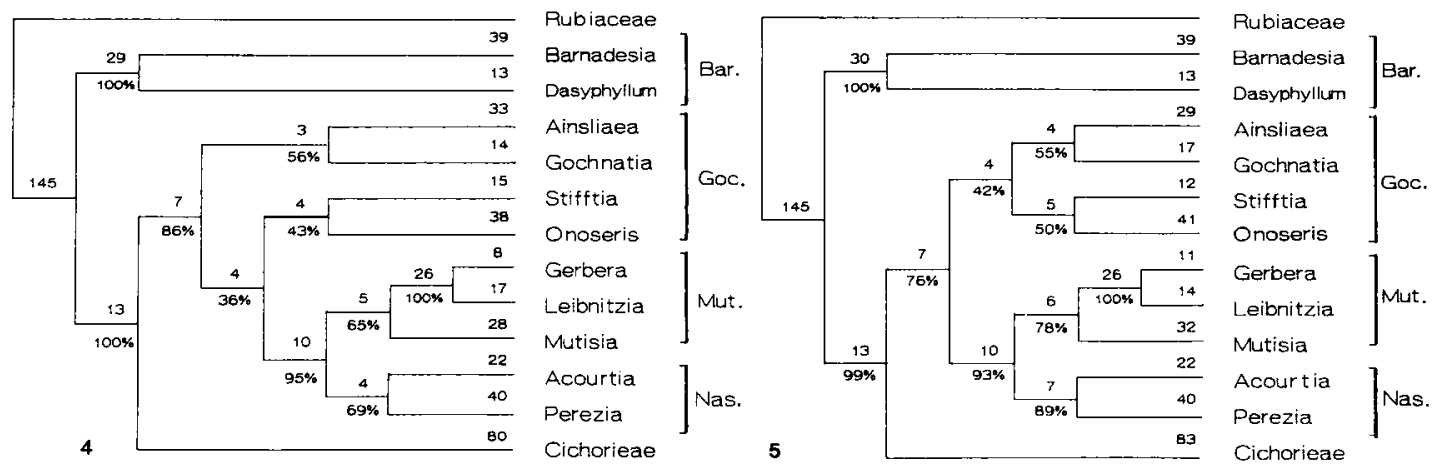

Fig. 2-5. Wagner and Dollo parsimony trees of the Asteraceae. The numbers at each node and along each lineage indicate the number of site mutations. The percentages indicate the number of times that a monophyletic group occurred in 100 bootstrap samples. Abbreviations for subtribes of Mutisieae: Bar, Barnadesiinae; Goc, Gochnatiinae; Mut, Mutisiinae; Nas, Nassauviinae. 2. Wagner parsimony tree for 16 species of Asteraceae using $211 \mathrm{cpDNA}$ restriction site mutations. This is the single most parsimonious tree generated by the branch-and-bound option of PAUP. The tree has 247 steps, including 27 parallel losses, two parallel gains, five gains/losses, and two losses/gains. 3. Dollo parsimony tree for 16 species of Asteraceae using 211 cpDNA restriction site mutations. This is the single most parsimonious tree generated by the global option of PHYLIP. The tree has 254 steps, including 44 convergent site losses or gains/losses. 4. Wagner parsimony tree for 12 species of Asteraceae using 390 cpDNA restriction site mutations. This is the single most parsimonious tree generated by the branch-and-bound option of PAUP. The tree has 454 steps, including 41 parallel losses, six parallel gains, nine gain/losses, and eight losses/gains. 5. Dollo parsimony tree for 12 species of Asteraceae using $390 \mathrm{cpDNA}$ restriction site mutations. This is the single most parsimonious tree generated by the global option of PHYLIP. The tree has 465 steps, including 76 convergent losses or gains/losses.

result is that the monophyletic group defined by the cpDNA inversion and six restriction site mutations is highly significant statistically (98 or $94 \%$ ) using both parsimony methods. This gives us great confidence in the basal evolutionary split in the Asteraceae suggested by the cpDNA inversion. Three monophyletic groups, the subtribe Barnadesiinae and the species pairs Gerbera/Leibnitzia and Barnadesia/Chuquiragua, are also highly significant (93-100\%). The remaining groups are much weaker statistically (Fig. 2, 3), including 37$48 \%$ for the Gochnatiinae, $48-56 \%$ for the Nas- sauviinae, $56-69 \%$ for the Mutisiinae, $52-72 \%$ for the Mutisiinae/Nassauviinae, and $46-50 \%$ for the group comprising all three of these subtribes in the Mutisiinae. Thus, although these groups share one to five derived restriction site mutations, they are not statistically significant in the bootstrap sample. The low confidence intervals for these groups is usually due to the problematical placement of one of their genera. The $56-69 \%$ interval for the Mutisiinae is caused primarily by Mutisia grouping with genera of the Nassauviinae in 37 (Dollo) or 18 (Wagner) of the bootstrap replicates. The very 
TABLE 4. Chloroplast DNA restriction site mutations used in phylogenetic analyses of 12 species of Asteraceae (species $1,3,4-12,14$ in Table 1) using 19 enzymes. Site changes in the $22 \mathrm{~kb}$ inversion region were not used because of the uncertainty of aligning rearranged sites. Only mutations shared by more than one species are listed. Mutations (145) shared by all species of Asteraceae relative to outgroup families and those (273) found in only a single species are not listed. Map coordinates in $\mathrm{kb}$ indicate the location of restriction site mutations (Fig. 1). Mutations are listed with the ancestral fragment(s) first, followed by the derived fragment(s). Ancestral states were determined by outgroup comparison (see Methods). Taxa sharing derived mutations are indicated by the numbers given in Table 1

\begin{tabular}{|c|c|c|c|c|c|c|c|}
\hline Enzyme $^{\mathrm{A}}$ & Region $^{\mathrm{b}}$ & Mutation & Mutated DNAs & Enzyme & Region ${ }^{b}$ & Mutation & Mutated DNAs \\
\hline 1. $\mathrm{A}$ & 82.7 & $0.9+0.5=1.4$ & 8,9 & 58. I & 122.6 & $3.7+1.8=5.5$ & $1,4,8-10$ \\
\hline 2. A & 91.2 & $6.3=3.5+2.8$ & 1,3 & & & & 12,14 \\
\hline \multirow[t]{2}{*}{ 3. $\mathrm{A}$} & 110.2 & $9.2=7.2+2.0$ & $3,4-11,12$ & 59. I & 44.5 & $11.5=8.5+2.8$ & 8,9 \\
\hline & & & 14 & 60. I & 44.7 & $11.5=8.7+2.9$ & 1,3 \\
\hline 4. $\mathrm{A}$ & 123.8 & $4.0+3.3=7.3$ & 7,9 & 61. I & 50.4 & $3.5=2.7+0.8$ & $4-12$ \\
\hline 5. A & 35.9 & $7.8+3.2=11.0$ & $8-12$ & 62. I & 51.9 & $0.8+0.7=1.5$ & $8-12$ \\
\hline 6. A & $39.6^{*}$ & $6.9=6.1+0.8$ & 8,9 & 63. I & $50.7^{*}$ & $0.8=0.5+0.3$ & 6,7 \\
\hline 7. $\mathrm{A}$ & 54.0 & $13.0=8.4+4.6$ & 1,3 & 64. I & 69.4 & $2.0+0.5=2.5$ & $10-12$ \\
\hline 8. A & 62.8 & $4.3+0.4=4.7$ & $4-7,14$ & 65. I & 77.5 & $7.0+2.1=9.1$ & 6,8 \\
\hline 9. A & 75.9 & $1.0+0.6=1.6$ & $8,9,12$ & 66. J & 81.6 & $1.4=1.0+0.4$ & 8,9 \\
\hline 10. $\mathrm{B}$ & 116.0 & $18=11.5+6.5$ & 1,3 & 67. J & $82.4^{* *}$ & $0.8=0.5+0.3$ & 1,3 \\
\hline \multirow{2}{*}{ 11. B } & 126.1 & $6.7+3.5=10.2$ & $8,10,11$ & 68. J & 101.1 & $8.9=5.0+3.9$ & 1,3 \\
\hline & & & 12,14 & 69. J & $115.9^{*}$ & $0.8+0.3=1.1$ & $5-7,8,9$ \\
\hline 12. $\mathrm{B}$ & 2.7 & $9.0=5.6+3.4$ & 1,3 & 70. $\mathrm{J}$ & 118.8 & $4.7+2.1=6.8$ & $3,9,12$ \\
\hline 13. $\mathrm{B}$ & 34.9 & $7.6+2.4=10.0$ & $6,11,12,14$ & 71. J & 123.8 & $1.5+1.4=2.9$ & $8,9,12$ \\
\hline 14. $B$ & 73.6 & $24=16+8$ & $8-12$ & 72. $\mathrm{J}$ & 67.2 & $1.2+0.7=1.9$ & $6-12$ \\
\hline 15. C & 60.3 & $2.9=1.6+1.3$ & 1,3 & 73. J & 68.2 & $3.5=1.9+1.6$ & $8-10$ \\
\hline 16. C & 77.1 & $3.6+3.0=6.6$ & 4,5 & 74. J & 68.4 & $3.5=1.8+1.7$ & 4,5 \\
\hline 17. C & 80.1 & $12.0+3.0=15.0$ & 1,7 & 75. J & $78.6^{* * *}$ & $0.8=0.4+0.4$ & $8-10$ \\
\hline 18. D & $37.8^{*}$ & $2.2=1.2+1.0$ & $4-10,14$ & 76. $\mathrm{K}$ & $90.9 * *$ & $1.1=0.7+0.4$ & $4,6,7$ \\
\hline 19. D & $51.8^{*}$ & $2.2=1.6+0.6$ & 1,3 & 77. $\mathrm{K}$ & $91.0^{* *}$ & $1.1=0.8+0.3$ & 12,14 \\
\hline 20. D & 61.5 & $3.0+1.8=4.8$ & 4,14 & 78. K & 110.6 & $4.0+1.5=5.5$ & $7,12,14$ \\
\hline 21. D & 80.7 & $2.5+0.3=2.8$ & $1,3,6$ & 79. $\mathrm{K}$ & 115.0 & $22+1.5=24$ & 4,7 \\
\hline 22. $\mathrm{D}$ & 77.9 & $4.0+1.4=5.4$ & 8,9 & 80. $\mathrm{K}$ & 119.2 & $22=17.5+4.2$ & $8-10$ \\
\hline 23. E & 85.3 & $1.2+0.9=2.1$ & $4-12,14$ & 81. $\mathrm{K}$ & 47.7 & $9.3=6.5+2.8$ & 1,3 \\
\hline 24. $E$ & 124.2 & $5.7=4.9+0.8$ & 8,9 & 82. $\mathrm{K}$ & $58.7^{* *}$ & $3.3=2.8+0.5$ & $4-12,14$ \\
\hline 25. E & 0.1 & $2.6=1.6+1.0$ & 1,3 & 83. $\mathrm{K}$ & 71.0 & $11.7=11.0+0.7$ & 8,9 \\
\hline \multirow[t]{2}{*}{ 26. $\mathrm{E}$} & 47.1 & $13.5=11.8+1.7$ & $4-6,8-12$ & 84. L & 0.2 & $10.0+5.4=15.4$ & 8,9 \\
\hline & & & 14 & 85. L & 28.4 & $6.4=3.4+3.0$ & 8,9 \\
\hline 27. $\mathrm{E}$ & 50.9 & $9.1=7.0+2.1$ & 8,9 & 86. L & 40.2 & $8.4=6.9+1.5$ & $4-12,14$ \\
\hline 28. $\mathrm{E}$ & 56.8 & $7.8+1.3=9.1$ & $6,8,9$ & 87. $\mathrm{M}$ & 83.5 & $2.4+2.2=4.6$ & 12,14 \\
\hline 29. E & 60.8 & $2.6+0.4=3.0$ & $8,9,14$ & 88. M & 110.4 & $6.3=4.8+1.5$ & $10-12$ \\
\hline \multirow[t]{2}{*}{ 30. $\mathrm{E}$} & 65.2 & $6.4=3.9+2.5$ & $5-7,8-11$ & 89. M & 110.6 & $20=18.3+1.7$ & 1,3 \\
\hline & & & 14 & 90. $\mathrm{M}$ & 115.2 & $11.7=6.3+5.4$ & $7,8-12$ \\
\hline 31. $\mathrm{E}$ & 71.0 & $6.0=4.9+1.1$ & 8,9 & 91. M & 120.4 & $12.0+8.0=20$ & $1,3,4$ \\
\hline 32. $\mathrm{E}$ & 74.5 & $6.0=4.6+1.4$ & 1,3 & 92. $\mathrm{M}$ & $55.6^{*}$ & $4.4=3.9+0.5$ & 6,9 \\
\hline 33. $\mathrm{F}$ & 84.3 & $6.4+3.0=9.4$ & $1,3,14$ & 93. $\mathrm{M}$ & 70.1 & $4.6=3.5+1.1$ & $8-12$ \\
\hline 34. F & 110.3 & $7.7=6.9+0.8$ & 1,3 & 94. $\mathrm{M}$ & 74.4 & $6.3+1.0=7.3$ & $1,8,9$ \\
\hline 35. $\mathrm{F}$ & 111.1 & $6.0+0.9=6.9$ & 8,10 & 95. $\mathrm{N}$ & 109.1 & $0.8+0.6=1.4$ & 1,3 \\
\hline 36. F & 124.5 & $8.0+6.3=14$ & $3,8,9$ & 96. $\mathrm{N}$ & 50.9 & $6.8=5.1+1.7$ & $4-11$ \\
\hline 37. $\mathrm{F}$ & 35.1 & $3.2+3.0=6.2$ & $7,8-12$ & 97. $\mathrm{N}$ & 60.6 & $2.4+1.8=4.2$ & 11,12 \\
\hline 38. $\mathrm{F}$ & 41.0 & $2.5+0.5=3.0$ & 7,12 & 98. $\mathrm{N}$ & 68.6 & $2.3+1.1=3.4$ & 4,14 \\
\hline 39. $\mathrm{G}$ & 86.0 & $2.3=1.3+1.0$ & $4,5,14$ & 99. $\mathrm{O}$ & 5.8 & $12.0=7.5+4.5$ & 8,9 \\
\hline 40. $\mathrm{G}$ & 93.3 & $1.7=1.1+0.6$ & 11,12 & 100. O & 68.7 & $7.2+1.0=8.2$ & $1,8-12$ \\
\hline 41. $\mathrm{G}$ & 107.8 & $2.5+0.3=2.8$ & 1,3 & 101. $\mathrm{O}$ & 73.1 & $11.7+3.3=14.0$ & 1,12 \\
\hline 42. $\mathrm{G}$ & 111.4 & $1.8=1.0+0.8$ & 1,3 & 102. P & 91.9 & $3.7+1.7=5.4$ & $1,3,5,8-10$ \\
\hline 43. $\mathrm{G}$ & 110.4 & $2.4=1.6+0.8$ & $4,6,7$ & 103. P & $101.3^{* *}$ & $5.7+0.8=6.5$ & 3,9 \\
\hline 44. $\mathrm{G}$ & 112.9 & $7.9=6.1+1.8$ & 1,3 & 104. $\mathrm{Q}$ & 110.6 & $6.0=4.2+1.8$ & 1,3 \\
\hline 45. G & 113.5 & $7.9=5.5+2.4$ & $4-12$ & 105. Q & $112.2^{*}$ & $6.0=3.4+2.6$ & 8,9 \\
\hline 46. $G$ & 122.4 & $4.5+3.4=7.9$ & 4,10 & 106. Q & 2.9 & $8.3=6.7+1.6$ & 1,3 \\
\hline 47. $G$ & 120.2 & $7.9+1.8=9.7$ & 3,4 & 107. Q & 66.0 & $4.9=3.7+1.2$ & $5-12,14$ \\
\hline 48. $\mathrm{G}$ & 47.4 & $1.0+0.7=1.7$ & 10,11 & 108. Q & 70.3 & $0.6+0.3=0.9$ & $1,3,8,9$ \\
\hline 49. G & 49.7 & $5.3=4.5+0.9$ & 1,3 & 109. R & 83.1 & $3.4=1.8+1.6$ & 11,12 \\
\hline 50. G & 57.6 & $3.9=3.3+0.6$ & $4-12,14$ & 110. R & 86.1 & $5.5=4.2+1.3$ & 1,3 \\
\hline 51. H & 109.5 & $4.0=2.2+1.8$ & $4-12$ & 111. $\mathrm{R}$ & 90.3 & $23+5.4=28$ & $4-12,14$ \\
\hline 52. $\mathrm{H}$ & 111.6 & $2.1+0.6=2.7$ & 9,14 & $112 . \mathrm{R}$ & 124.4 & $28+8.7=36$ & 1,3 \\
\hline 53. $\mathrm{H}$ & 112.2 & $6.7=6.1+0.6$ & $4-11$ & $113 . \mathrm{R}$ & 54.3 & $7.8=6.2+1.6$ & 1,3 \\
\hline 54. H & 113.1 & $6.1=5.2+0.9$ & $4-6$ & 114. R & 59.0 & $2.5+2.2=4.7$ & $8,9,12,14$ \\
\hline
\end{tabular}


TABLE 4. Continued

\begin{tabular}{lrllllll}
\hline \hline Enzyme $^{*}$ & Region $^{\mathrm{b}}$ & \multicolumn{1}{c}{ Mutation } & Mutated DNAs & \multicolumn{1}{c}{ Enzyme $^{\mathrm{a}}$} & \multicolumn{1}{c}{ Region $^{\mathrm{b}}$} & \multicolumn{1}{c}{ Mutation } & Mutated DNAs \\
\hline 55. H & 118.1 & $9.5+6.0=15.5$ & 8,9 & $115 . \mathrm{R}$ & 66.5 & $5.0=3.6+1.4$ & $4-10,12,14$ \\
56. H & 78.1 & $10.4=5.8+4.6$ & $4-12,14$ & $116 . \mathrm{R}$ & $80.1^{*}$ & $3.1=2.5+0.6$ & 8,9 \\
57. I & 84.2 & $7.0=5.7+1.3$ & 1,3 & $117 . \mathrm{S}$ & 4.1 & $8.3=6.3+2.0$ & 8,9 \\
\hline
\end{tabular}

a Enzyme abbreviations: A = AvaI; B = BamHI; C = BanI; D = BanII; E = BclI; F = BglII; G = BstNI; H = BstXI; $\mathrm{I}=\mathrm{ClaI} ; \mathrm{J}=\mathrm{EcoRI}$ $\mathrm{K}=\mathrm{EcoRV} ; \mathrm{L}=$ HaeII; $\mathrm{M}=$ HgiAI; $\mathrm{N}=$ HincII; $\mathrm{O}=$ HindIII; $\mathrm{P}=\mathrm{NcoI} ; \mathrm{Q}=\mathrm{NsiI} ; \mathrm{R}=\mathrm{XbaI}$; $\mathrm{S}=$ XhoI.

${ }^{\mathrm{b}}$ Ambiguity concerning region because two* or three**, or four*** restriction fragments are unordered.

low confidence intervals for the Gochnatiinae can be attributed primarily to Onoseris, which does not group consistently with any other genus and is placed outside of this subtribe in 41 (Dollo) or 45 (Wagner) of the bootstrap samples.

The phylogenetic analyses using 10 restriction enzymes provide strong statistical support for a number of monophyletic groups within the Asteraceae. However, the relationships of several taxa (Mutisia, Onoseris, etc.) were not satisfactorily resolved. In order to clarify the relationships of these problematical taxa, cpDNAs of thirteen species (numbers 1, 3-12, 15, 19 in Table 1) were examined using nine additional six-base pair restriction enzymes. Approximately 600 sites were mapped in cpDNAs of each species for the 19 enzymes. A total of 390 site mutations were detected in the Asteraceae, 117 of which are phylogenetically informative (Table 4). The direction of evolutionary change of restriction sites was determined by comparison to only one outgroup, a member of the Rubiaceae, for the nine additional enzymes. The data were again subjected to Wagner and Dollo parsimony and the bootstrap sampling method.

The Wagner analysis produced a single most parsimonious tree of 454 steps (Fig. 4), which has a consistency index of 0.86 and $14 \%$ homoplasy. There are 64 homoplasious site changes, including 41 parallel losses, six parallel gains, nine gains/losses, and eight losses/ gains. The overall tree topology (Fig. 4) is nearly identical to the tree constructed using only nine enzymes and 55 informative site changes (Fig. 2). The initial dichotomy separating the Barnadesiinae from the rest of the Asteraceae is supported by seven additional restriction site mutations. The forced topology option of PAUP showed that 12 additional steps (466 total steps) are required to break this primary evolutionary split in the Asteraceae. The monophyletic group comprising the three subtribes of the Mutisieae with the cpDNA inversion (Gochnatiinae, Mutisiinae, and Nassauviinae) is supported by five more site changes. There are also more restriction site mutations supporting the monophyly of the subtribes Mutisiinae and Nassauviinae, whereas the Gochnatiinae is again shown to be paraphyletic (compare Fig. 2, 4). Stifftia and Onoseris group with the Mutisiinae and Nassauviinae, and Ainsliaea and Gochnatia form a separate monophyletic group. Dollo parsimony produced a single most parsimonious tree (Fig. 5) that is 11 steps (465 total steps) longer than the Wagner tree. The Dollo tree has a consistency index of 0.84 and $16 \%$ homoplasy. The topologies of the Wagner and Dollo trees (Fig. 4, 5) are identical except for the positioning of the four genera in the Gochnatiinae. Dollo parsimony places these taxa in a monophyletic group defined by four restriction site mutations.

The majority-rule consensus trees constructed from 100 bootstrap samples are identical to the most parsimonious trees for both Wagner (Fig. 4) and Dollo (Fig. 5) parsimony. The four monophyletic groups that are highly significant ( $95 \%$ or above) for the 10 enzyme analyses have even higher confidence intervals for the 19 enzyme data set (compare Fig. 2-5). This includes the group that shares the derived cpDNA inversion, which has confidence intervals of 99 and $100 \%$ for Dollo and Wagner parsimony, respectively. The larger data set provides much stronger support for the monophyly of the group consisting of the Gochnatiinae, Mutisiinae, and Nassauviinae (76$86 \%$ ). Relationships among the four genera of the Gochnatiinae are not fully resolved by these analyses. There is little statistical support for the monophyly of the Gochnatiinae $(42 \%$ in Fig. 5) or the close relationship of Onoseris/ Stifftia to the subtribes Mutisiinae and Nassauviinae (36\% in Fig. 4). Inspection of the 100 trees in the bootstrap sample reveals that Onoseris groups with either Stifftia or the group consisting of the five genera of the Mutisiinae and Nassauviinae in 97 or $99 \%$ of the samples for Dollo and Wagner parsimony, respectively. Thus, we can conclude that Onoseris belongs in one of these two groups. 
Discussion-Phylogenetic implications of $c p D N A$ mutations - The phylogenetic analysis of cpDNA restriction site mutations provides valuable insights into evolutionary relationships within the Asteraceae. The identification of the ancestral lineage within the family has been one of the most controversial systematic issues. The Heliantheae has frequently been proposed as the basal tribe (Koch, 1930; Cronquist, 1955, 1977; Wagenitz, 1976) because it possesses a number of putatively primitive morphological and anatomical features, including a woody habit, opposite leaves, leafy involucre, chaffy receptacle, connate anthers without tails, styles without differentiated stigmatic portions, and a 5-parted, chaffy pappus. Four other tribes, the Cardueae, Mutisieae, Senecioneae, and Vernonieae, have also been proposed as being ancestral (Cronquist, 1955; Carlquist, 1976; Wagenitz, 1976; Jeffrey, 1977). The most significant result of our cpDNA restriction site analyses is the overwhelming confirmation of an ancient evolutionary split in the Asteraceae that was first suggested by the distribution of a single cpDNA inversion (Jansen and Palmer, 1987b). Statistical analyses using the bootstrap method (Fig. 2-5) give us great confidence that the Barnadesiinae is the ancestral lineage within the family. Furthermore, congruence of our molecular phylogeny and Bremer's (1987) cladogram based primarily on morphological characters provides additional support for the basal position of the Barnadesiinae.

The identification of the Barnadesinae as the ancestral lineage has important implications concerning the place of origin of the Asteraceae and its relationships to other families in the Asteridae. The center of diversity for the eight genera of Barnadesiinae is the northern Andes (Cabrera, 1977), which supports previous suggestions that the family originated in montane South America (Bentham, 1873; Small, 1919; Raven and Axelrod, 1974; Turner, 1977). Our results also agree with suggestions (Carlquist, 1966; 1976; Jeffrey, 1977) that bilabiate flowers and the woody habit, which are common features in the Barnadesiinae, are primitive in the Asteraceae. This indicates affinities between the Asteraceae and the families with some bilabiate or woody members, including the Campanulaceae, Lobeliaceae, Goodeniaceae, and Stylidaceae. Bremer (1987) has argued that the Lobeliaceae is the most closely related family because it shares several putatively derived characters with the Asteraceae, including apically thickened and shortly bilobed styles and persistently connate anthers. These style characters are present in many $\mathrm{Mu}$ - tisieae, especially members of the subtribe Barnadesiinae (Bremer, 1987).

The phylogenies generated using restriction site mutations also provide insights into relationships within the Mutisieae. Our results confirm previous suggestions (Small, 1918; Wodehouse, 1928; Cabrera, 1977; Bremer, 1987; Jansen and Palmer, 1987b) that the Mutisieae is not monophyletic, because three of its four subtribes are more closely related to other tribes of the Asteraceae than they are to the Barnadesiinae (Fig. 2-5). Several unique morphological features, including nodal spines, floral parts with long villous pubescence, spineless pollen with intercolpar depressions, and modified bilabiate corollas, support the distant relationship of Barnadesiinae to the rest of the Asteraceae. The cpDNA phylogeny (Fig. 4, 5) supports the monophyly of three of the four currently recognized subtribes (sensu Cabrera, 1977) of the Mutisieae. The monophyly of the Barnadesiinae is statistically highly significant, whereas the Mutisiinae and Nassauviinae are much weaker groups. Although these two subtribes are each only weakly monophyletic groups, it is notable that the two together constitute one of the strongest clades (Fig. 4, 5). This finding is consistent with Cabrera's (1977) suggestion that the subtribes Mutisiinae and Nassauviinae are closely related.

The four genera of the Gochnatiinae are grouped together using Dollo parsimony (Fig. 3,5 ), but there is little statistical support for their monophyly. Bremer (1987) considered the 58 genera of this subtribe to be paraphyletic, a suggestion supported by the diverse morphology and wide geographic distribution of the Gochnatiinae. The four genera we analyzed consistently fall into two groups, one including Onoseris and Stifftia and the second including Gochnatia and Ainsliaea. These groups correspond to the subtribes Gochnatiinae and Onoseridinae recognized by Bentham (1873) and Small (1919). Furthermore, Small (1919) proposed a close relationship between Onoseris and the Mutisiinae (= Gerberinae), which is supported by our bootstrap analyses in that Onoseris groups consistently with either Stifftia or the Mutisiinae and Nassauviinae. Further clarification of phylogenetic relationships within the Gochnatiinae will require examination of cpDNAs from more of its 54 other genera.

There have been very few studies of intergeneric relationships within the four subtribes of the Mutisieae. The most extensive investigation involved a cladistic analysis of morphological characters for the 23 genera of the Nassauviinae (Crisci, 1980). The close rela- 
TABLE 5. Sequence divergence between cpDNAs from species in the Asteraceae. Genera are abbreviated by their first three letters. The number of restriction site mutations between cpDNAs from the Dollo parsimony tree (Fig. 5) is indicated in the upper right portion of matrix. Nei and Li (1979) divergence values are given as $100 \mathrm{p}$ in the lower portion of the matrix. Approximately 600 restriction sites were examined for each species. Restriction sites in the $22 \mathrm{~kb} c \mathrm{cDNA}$ inversion were not used in the calculations because of difficulty in aligning the rearranged sites

\begin{tabular}{lcccccccrrrrr}
\hline \hline & Bar & Das & Ain & Goc & Sti & Ono & Ger & Lei & Mut & Aco & Per & Lac \\
\hline Bar & - & 52 & 126 & 114 & 110 & 139 & 142 & 145 & 137 & 128 & 146 & 165 \\
Das & 1.5 & - & 100 & 88 & 84 & 113 & 116 & 119 & 111 & 102 & 120 & 139 \\
Ain & 3.9 & 3.0 & - & 46 & 50 & 79 & 90 & 93 & 85 & 76 & 94 & 127 \\
Goc & 3.5 & 2.6 & 1.3 & - & 38 & 67 & 78 & 81 & 73 & 64 & 82 & 115 \\
Sti & 3.4 & 2.5 & 1.4 & 1.1 & - & 53 & 74 & 77 & 69 & 60 & 78 & 111 \\
Ono & 4.4 & 3.5 & 2.3 & 2.0 & 1.5 & - & 103 & 106 & 98 & 89 & 107 & 140 \\
Ger & 4.5 & 3.6 & 3.0 & 2.3 & 2.2 & 3.1 & - & 25 & 69 & 72 & 90 & 143 \\
Lei & 4.6 & 3.7 & 2.8 & 2.4 & 2.3 & 3.2 & 0.7 & - & 72 & 75 & 93 & 146 \\
Mut & 4.3 & 3.4 & 2.5 & 2.2 & 2.0 & 3.0 & 2.0 & 2.1 & - & 67 & 85 & 138 \\
Aco & 4.0 & 3.1 & 2.3 & 1.9 & 1.8 & 2.7 & 2.1 & 2.2 & 2.0 & - & 62 & 129 \\
Per & 4.5 & 3.7 & 2.8 & 2.4 & 2.3 & 3.3 & 2.7 & 2.8 & 2.5 & 1.8 & - & 147 \\
Lac & 5.4 & 4.4 & 4.0 & 3.5 & 3.4 & 4.4 & 4.5 & 4.6 & 4.4 & 4.0 & 4.7 & - \\
\hline
\end{tabular}

tionship of Perezia and Trixis in our cpDNA phylogenies (Fig. 2, 3) agrees with Crisci's (1980) placement of these genera in the same lineage. The systematic relationship of Barnadesia has been controversial because of its distinctive pollen (Wodehouse, 1928; 1929) and floral (Small, 1918) morphology. Wodehouse was so impressed by the unique pollen in the genus that he suggested that it has no clear relationship to any genus of Mutisieae. The cpDNA data (Fig. 2,3) show a strong affinity between Barnadesia and Chuquiragua, which has been less explicitly indicated by Chung (1965) and Cabrera (1977). A close relationship is also evident between Gerbera and Leibnitzia (Fig. 2-5). Both genera are part of the Gerbera group (sensu Jeffrey, 1967), which consists of seven genera from the New and Old Worlds. Although the species of Leibnitzia examined in this study is from Mexico (Table 1), four species are native to Asia. Gerbera is a large genus ( 35 species) that is widespread in Asia, Madagascar, and Africa (Cabrera, 1977). The low level of sequence divergence between these genera $(0.7 \%$, Table 5$)$ indicates that they have recently diverged from each other. This is significant biogeographically because it suggests that the Mexican species of Leibnitzia reached North America via a recent long distance dispersal from one of the Asian species. If vicariance were involved, one would expect Gerbera and Leibnitzia to have a higher level of nucleotide change than in pairwise comparisons of the New World genera of the $\mathrm{Mu}$ tisieae (Table 5).

$C p D N A$ sequence divergence-Sequence divergence values $(100 \mathrm{p}$ using equations 9 and 10 of Nei and Li, 1979) among 12 species of Asteraceae ranged from $0.7-5.4 \%$ (Table 5).
This level of nucleotide change among genera in different subtribes and tribes is surprisingly low in comparison to intrageneric divergence values in several other angiosperm families. Previous estimates include $0-0.7 \%$ in $\mathrm{Lyco}$ persicon (Palmer and Zamir, 1982), 0.3-2.6\% in Brassica (Palmer et al., 1983a), 0-0.3\% in Lisianthius (Sytsma and Schaal, 1985), 0.2$1.5 \%$ in Clarkia (Sytsma and Gottlieb, 1986b), $0-6 \%$ in Linum (Coates and Cullis, 1987), and $0.2-4.4 \%$ in Atriplex (J. Palmer, unpublished data). Intergeneric divergence values among three genera from a single tribe in the Fabaceae (Palmer, Singh, and Pillay, 1983b) are substantially higher $(5.5 \%$ and $10.8 \%)$ than our estimates within the Asteraceae. The low levels of nucleotide change in the Asteraceae suggest that lineages within the family are relatively more recent than those in previously studied angiosperm families. An alternative explanation is that the rate of cpDNA divergence is slower within the Asteraceae.

Sequence divergence among the genera within the Asteraceae (Table 5) generally reflects the cladistic relationships among these taxa as depicted in Fig. 5. The high level of nucleotide change between the Barnadesiinae and the three subtribes of Mutisieae with the cpDNA inversion further support the distant relationship of the Barnadesiinae (Table 5). The range of divergence values between the Barnadesiinae and the other three subtribes is between 2.5$4.6 \%$, whereas the values among the subtribes Gochnatiinae, Mutisiinae, and Nassauviinae are $1.8-3.2 \%$. As expected, the level of nucleotide change is much less among genera within the subtribes of the Mutisieae. The lowest divergence value is between Gerbera and Leibnitzia in the Mutisiinae. A close relationship between these genera has already been 
suggested by Jeffrey (1967) and Cabrera (1977). There are several incongruities between the cladistic relationships among taxa and the distances between them based on cpDNA sequence divergence. For example, divergence values (Table 5) indicate a more distant relationship between Stifftia and Onoseris (1.5\%) than between Stifftia and Gochnatia (1.1\%), which differs from the cladistic placement of these genera (Fig. 5). The incongruities could reflect differential rates of cpDNA sequence evolution within different lineages. We will address these quantitative issues in a subsequent paper on the tempo and mode of cpDNA evolution in the Mutisieae and other Asteraceae.

\section{Limitations of Wagner and Dollo parsi-} mony - Most of the homoplasious cpDNA restriction site mutations in the Asteraceae are site losses. This is expected because of the much higher probability of convergent site losses than convergent gains (DeBry and Slade, 1985). Unfortunately, neither Dollo nor Wagner parsimony is ideal for phylogenetic analyses of restriction site data, especially at higher taxonomic levels. Wagner parsimony is not appropriate because it gives equal weight to both convergent gains and losses. This can result in a tree with a large number of convergent gains, which is the situation for the Asteraceae cpDNA phylogeny (Fig. 4, with 14 homoplasious gains out of 64 homoplasious changes). Dollo parsimony is too rigid in the other direction because it completely prohibits parallel gains. Although there is a very low probability of convergent gains, they can occur occasionally, especially in comparisons of distantly related taxa. Furthermore, two different site gains could occur in two or more unrelated species at approximately the same position in the genome, resulting in nearly equal sized restriction fragments that could not be distinguished using our gel system. Additional mapping experiments using higher percentage agarose and longer gels, and double enzyme digests might enable one to determine whether these sites are truly homologous. In the absence of such information, it might be best to provisionally treat these site changes as homologous gains rather than invoking a single site gain followed by a number of convergent losses. A parsimony algorithm that gives differential weights to homoplasious gains vs. losses would be preferable. David Swofford (personal communication) is currently developing such a program for his new microcomputer version of PAUP.

Phylogenetic utility of $c p D N A-A$ number of studies have demonstrated the potential of
cpDNA restriction site mutations for resolving phylogenetic relationships among closely related species (reviewed in Palmer, 1986b; 1987). Highly informative and statistically significant cpDNA phylogenies with very low levels of homoplasy have been generated in several genera, e.g., 3\% in Lycopersicon (Palmer and $\mathrm{Za}$ mir, 1982), 2\% in Brassica (Palmer et al., 1983a), and 5\% in Clarkia (Sytsma and Gottlieb, 1986b). Our studies in the Asteraceae are the first to analyze cpDNA restriction site mutations at the tribal and subtribal levels. Although there is clearly an increased incidence of homoplasy $(14-17 \%)$, it is evident that cpDNA can still provide substantial phylogenetic insights at higher taxonomic levels. The level of homoplasy in restriction sites between tribes and subtribes is significantly lower than for morphological characters among closely related species of Asteraceae, e.g., $80 \%$ homoplasy in Montanoa (Funk, 1982), 50\% in ACmella (Jansen, 1985), and 57\% in Coreopsis (Jansen, Smith, and Crawford, 1987).

\section{LITERATURE CITED}

Bentham, G. 1873. Notes on the classification, history and geographical distribution of the Compositae. Bot. J. Linn. Soc. 13: 335-577.

Boulter, D., J. T. Gleaves, B. C. Haslett, D. Peacock, AND U. JENSEN. 1978. The relationships of 8 tribes of the Compositae as suggested by plastocyanin amino acid sequence data. Phytochem. 17: 1585-1589.

Bowman, C. M., G. Bonnard, AND T. A. Dyer. 1983. Chloroplast DNA variation between species of Triticum and Aegilops. Location of the variation on the chloroplast genome and its relevance to the inheritance and classification of the cytoplasm. Theor. Appl. Genet. 65: 247-262.

Bremer, K. 1987. Tribal interrelationships of the Asteraceae. Cladistics 3: 210-253.

Cabrera, A. L. 1977. Mutisieae-systematic review. In V. H. Heywood, J. Harborne, and B. L. Turner [eds.], The biology and chemistry of the Compositae, 10391066, Vol. 2. Academic Press, New York.

Carlquist, S. 1966. Wood anatomy of the Compositae: a summary, with comments on factors controlling wood evolution. Aliso 6: 25-44.

- 1976. Tribal interrelationships and phylogeny of the Asteraceae. Aliso 8: 465-492.

Chung, I. 1965. Revision of Barnadesia. Taesutang Press, Seoul, Korea.

Coates, D., and C. A. Cullis. 1987. Chloroplast DNA variability among Linum species. Amer. J. Bot. 74: 260-268.

Crisci, J. V. 1980. Evolution in the subtribe Nassauviinae (Compositae, Mutisieae): A phylogenetic reconstruction. Taxon 29: 213-224.

Cronguist, A. 1955. Phylogeny and taxonomy of the Compositae. Amer. Midl. Naturalist 53: 478-511.

- 1977. The Compositae revisited. Brittonia 29: $137-153$.

1981. An integrated system of classification of flowering plants. Columbia University Press, New York. 
DAHLGREN, R. 1980. A revised system of classification of the angiosperms. Bot. J. Linn. Soc. 80: 91-124.

DeBry, R. W., and N. A. Slade, 1985. Cladistic analysis of restriction endonuclease cleavage maps within a maximum-likelihood framework. Syst. Zool. 34: 2134.

Felsenstein, J. 1985. Confidence limits on phylogenies: an approach using the bootstrap. Evolution 39: 783791.

Funk, V. A. 1982. The systematics of Montanoa (Asteraceae, Heliantheae). Mem. New York Bot. Gard. 36: $1-133$.

Hendy, M. D., And D. Penny. 1982. Branch and bound algorithms to determine minimal evolutionary trees. Math. Biosci. 59: 277-290.

HosAKA, K. 1986. Who is the mother of the potato?restriction endonuclease analysis of chloroplast DNA of cultivated potatoes. Theor. Appl. Genet. 72: 606618.

— Y. Ygihara, M. Matsubayashi, and K. TsunewAKI. 1984. Phylogenetic relationship between the tuberous Solanum species as revealed by restriction endonuclease analysis of chloroplast DNA. J. Genet. (Japan) 59: 349-369.

JANSEN, R. K. 1985. The systematics of Acmella (Asteraceae-Heliantheae). Syst. Bot. Monog. 8.

$\longrightarrow$, E. B. SMITh, AND D. J. CRAwFord. 1987. A cladistic study of North American Coreopsis (Asteraceae:Heliantheae). P1. Syst. Evol. 157: 73-84.

$\longrightarrow$, AND J. D. PAlmer. 1987a. Chloroplast DNA from lettuce and Barnadesia (Asteraceae): structure, gene localization, and characterization of a large inversion. Curr. Genet. 11: 553-564.

— AND —. 1987b. A chloroplast DNA inversion marks an ancient evolutionary split in the sunflower family (Asteraceae). Proc. Natl. Acad. Sci. USA 84: 5818-5822.

Jefreey, C. 1967. Notes on Compositae: II. The Mutisieae in east tropical Africa. Kew Bull. 21: 177-223.

- 1977. Corolla forms in Compositae-some evolutionary and taxonomic speculations. In V. H. Heywood, J. Harborne, and B. L. Turner [eds.], The biology and chemistry of the Compositae, 111-118, Vol. 1. Academic Press, New York.

- 1978. Compositae. In V. H. Heywood [ed.], Flowering plants of the world, 263-268. Mayflower Books, New York.

KLuge, A. G., ANd J. S. Farris. 1969. Quantitative phyletics and the evolution of anurans. Syst. Zool. 18: 132.

$\mathrm{KoCH}$, M. F. 1930. Studies of the anatomy and morphology of the compositae flower II. The corollas of the Heliantheae and Mutisieae. Amer. J. Bot. 17: 938952.

Kung, S. D., Y. S. Zhu, AND K. Chen. 1982. Nicotiana chloroplast genome III. Chloroplast DNA evolution. Theor. Appl. Genet. 61: 73-79.

MUller, J. 1981. Fossil pollen records of extant angiosperms. Bot. Rev. 47: 1-142.

NeI, M., AND W. LI 1979. Mathematical models for studying genetic variation in terms of restriction endonucleases. Proc. Natl. Acad. Sci. USA 76: 52695273.

PAlmer, J. D. 1985a. Comparative organization of chloroplast genomes. Annual Rev. Genet. 19: 325-354.

1985b. Evolution of chloroplast and mitochondrial DNA in plants and algae. In R. J. MacIntyre [ed.], Molecular evolutionary genetics, 131-240. Plenum, New York. 1986a. Isolation and structural analysis of chloroplast DNA. Meth. Enzymol. 118: 167-186.

- 1986b. Chloroplast DNA and phylogenetic relationships. In S. K. Dutta [ed.], DNA systematics: evolution, 63-80. CRC Press, Boca Raton, FL.

- 1987. Chloroplast DNA evolution and biosystematics uses of chloroplast DNA variation. Amer. Naturalist 130: S6-S29.

- R. A. JoRgENSEN, AND W. F. ThompSon. 1985. Chloroplast DNA variation and evolution in Pisum: patterns of change and phylogenetic analysis. Genetics 109: 195-213.

$\longrightarrow$, C. R Shields, D. B. Cohen, ANd T. J. Orton. 1983a. Chloroplast DNA evolution and the origin of amphidiploid Brassica species. Theor. Appl. Genet. 65: 181-189.

- G. P. Singh, AND D. T. N. Pillay. 1983b. Structure and sequence evolution of three legume chloroplast DNAs. Molec. Gen. Genet. 190: 13-19.

, AND D. ZAMIR. 1982. Chloroplast DNA evolution and phylogenetic relationships in Lycopersicon. Proc. Natl. Acad. Sci. USA 79: 5006-5010.

Perl-Treves, R., and E. Galun. 1985. The Cucumis plastome: physical map, intrageneric variation and phylogenetic relationships. Theor. Appl. Genet. 71: 417-429.

Raven, P. H., AND D. I. Axelrod. 1974. Angiosperm biogeography and past continental movements. Ann. Missouri Bot. Gard. 61: 539-673.

Saghai-Maroof, M. A., K. M. Soliman, R. A. Jorgensen, AND R. W. Allard. 1984. Ribosomal DNA spacer length polymorphisms in barley: Mendelian inheritance, chromosomal location, and population dynamics. Proc. Natl. Acad. Sci. USA 81: 8014-8018.

Salts, Y., R. G. Herrmann, N. Peleg, U. Lavi, S. Izhar, R. Frankel, and J. S. Bechmann. 1984. Physical mapping of plastid DNA variation among eleven $\mathrm{Ni}$ cotiana species. Theor. Appl. Genet. 69: 1-14.

Shinozak, K., M. Ohme, M. Tanaka, T. Wakasugi, N. Hayashida, T. Matsubuyashi, N. Zaita, J. Chunwongse, J. Obokata, K. YamaguchiShinozaki, C. Ohto, K. Torazawa, B. Y. Meng, M. Sugita, H. Deno, T. Kamogashira, K. Yamada, J. Kusuda, F. Takaiwa, A. Kato, N. Tohdoh, H. ShIMODA, AND M. SUGIURA. 1986. The complete nucleotide sequence of the tobacco chloroplast genome: its gene organization and expression. EMBO J. 5: 20432049.

SMaLl, J. 1918. The origin and development of the Compositae. Chapter IV. The corolla. New Phytol. 17: 1340.

1919. The origin and development of the Compositae. Chapter XIII. General conclusions. New Phytol. 18: 201-234.

Stafleu, F. 1981. Index Herbariorum. W. Junk, Dordrecht.

Stevens, P. F. 1980. Evolutionary polarity of character states. Annual Rev. Ecol. Syst. 11: 333-358.

SytSMA, K. J., AND L. D. GotTlieb. 1986a. Chloroplast DNA evidence for the derivation of the genus Heterogaura from Clarkia (Onagraceae). Proc. Natl. Acad. Sci. USA 83: 5554-5557.

$\longrightarrow$, AND —. 1986b. Chloroplast DNA evolution and phylogenetic relationships in Clarkia sect. Peripetasma (Onagraceae). Evolution 40: 1248-1262.

$\longrightarrow$, AND B. A. SCHAAL. 1985. Phylogenetics of the Lisianthius skinneri (Gentianaceae) species complex in Panama using DNA restriction fragment analysis. Evolution 39: 594-608. 
TakHTAjan, A. L. 1980. Outline of the classification of flowering plants (Magnoliophyta). Bot. Rev. 46: 225359.

THORNe, R. F. 1976. A phylogenetic classification of the Angiosperms. Evol. Biol. 9: 35-106.

. 1983. Proposed new realignments in the angiosperms. Nord. J. Bot. 3: 85-117.

TsunewaKi, K., AND Y. OGIHARA. 1983. The molecular basis of genetic diversity among cytoplasms of Triticum and Aegilops species. II. On the origin of polyploid wheat cytoplasms as suggested by chloroplast DNA restriction fragment patterns. Genetics 104: 155171.

TuRNER, B. L. 1977. Fossil history and geography. In V. H. Heywood, J. Harborne, and B. L. Turner [eds.],
The biology and chemistry of the Compositae, 2139, Vol. 1. Academic Press, New York.

WAGENITZ, G. 1976. Systematics and phylogeny of the Compositae (Asteraceae). Pl. Syst. Evol. 125: 29-46. 1977. New aspects of the systematics of Asteridae. Pl. Syst. Evol. Suppl. 1: 375-395.

Watrous, L., AND Q. WhEeler. 1981. The out-group comparison method of character analysis. Syst. Zool. 30: 1-11.

WODEhouse, R. P. 1928. Pollen grains in the identification and classification of plants. II. Barnadesia. Bull. Torrey Bot. Club 55: 449-462.

. 1929. Pollen grains in the identification and classification of plants. IV. The Mutisieae. Amer. J. Bot. 16: 297-312. 